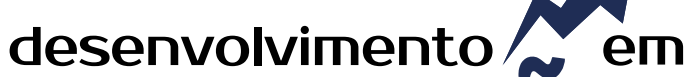 QUESTÂOO
}

\section{O APELO SOCIOECONÔMICO E A AÇÃO EMPREENDEDORA NO PROCESSO DE ESTRUTURAÇÃO DE CONFIGURAÇÕES PRODUTIVAS VINCULADAS À BIOENERGIA NO BRASIL}

\author{
http://dx.doi.org/10.21527/2237-6453.2021.55.10185
}

Recebido em: 5/2/2020

Aceito em: $13 / 4 / 2021$

\author{
Fábio Freitas Schilling Marquesan¹, Joselito Brilhante Silva²
}

\begin{abstract}
RESUMO
O crescimento da população fez o mundo perceber um forte aumento na demanda por energia. A maior parte da atual demanda de energia é atendida pela queima de combustíveis fósseis. O uso de combustíveis tradicionais, no entanto, está associado a um aumento ambiental na intensidade de gases nocivos, como dióxido de carbono, gases de efeito estufa e óxido de nitrogênio. O objetivo deste ensaio é problematizar o que ficou denominado de apelo socioeconômico associado à ação empreendedora, que é dirigida à estruturação de determinadas configurações produtivas orientadas à exploração da bioenergia no Brasil. Tal objetivo justifica-se na medida em que problematiza a maneira como ocorrem os processos que tendem a estimular o uso de fontes e formas alternativas de produção bioenergética. A fim de sustentar essa justificativa, este ensaio aborda o apelo socioeconômico da produção bioenergética no Brasil, o processo de mudança na perspectiva institucional e o empreendedor como agente de mudanças institucionais e inovações sociais. O resultado deste trabalho proporciona subsídios acerca da reflexão, que deve perpassar a busca de soluções consensuais e negociadas para os problemas que foram levantados quanto à exploração da bioenergia no Brasil. O ensaio apresenta-se como um veículo indicativo de como podem vir a ser conduzidas as transformações de ordem social com a proposição de uma reflexão sobre as soluções que têm sido desenvolvidas para resolver, de forma sustentável, os problemas relacionados à exploração da bioenergia no Brasil.
\end{abstract}

Palavras-chave: Bioenergia. Configurações produtivas. Empreendedorismo.

\section{SOCIOECONOMIC APPEAL AND ENTREPRENEURIAL ACTION IN THE PROCESS OF STRUCTURING PRODUCTIVE CONFIGURATIONS LINKED TO BIOENERGY IN BRAZIL}

\begin{abstract}
The increase in population has made a world perceive a strong increase in the demand for energy. Most of the current energy demand is met by burning fossil fuels. However, the use of traditional fuels is associated with an environmental increase in the intensity of harmful gases, such as carbon dioxide, greenhouse gases and nitrogen oxide. The objective of this essay is to problematize what became known as socioeconomic appeal associated with entrepreneurial action, which is aimed at structuring certain productive configurations oriented to the exploration of bioenergy in Brazil. This objective is justified insofar as it questions the way in which the processes that tend to stimulate the use of alternative sources and forms of bioenergetic production occur. In order to support this justification, this essay addresses the socioeconomic appeal of bioenergetic production in Brazil; the process of change in the institutional perspective; and, the entrepreneur as an agent of institutional changes and social innovations. The result of this work provides subsidies about the reflection that must go through the search for consensual and negotiated solutions to the problems that have been raised regarding the exploration of bioenergy in Brazil. The essay presents itself as a vehicle that indicates how social transformations can be conducted with the proposal of a reflection on the solutions that have been developed to solve, in a sustainable way, the problems related to the exploration of bioenergy in Brazil.
\end{abstract}

Keywords: Bioenergy. Productive configurations. Entrepreneurship.

\footnotetext{
${ }^{1}$ Universidade de Fortaleza (Unifor). Fortaleza/CE, Brasil. http://lattes.cnpq.br/0801248403289252. https://orcid.org/0000-00022456-4914.marquesan@unifor.br

${ }^{2}$ Autor correspondente. Instituto Federal de Educação, Ciência e Tecnologia do Ceará - IFCE Campus Quixadá. Estrada do Açude Cedro, km 5 - Cedro Novo. Quixadá/CE, Brasil. CEP 63900-000. http://lattes.cnpq.br/7274145339756425. http://orcid.org/00000001-6856-7562. joselito@ifce.edu.br
} 


\section{INTRODUÇÃO}

O crescimento da população fez o mundo perceber um forte aumento na demanda por energia. A maior parte da atual demanda de energia é atendida pela queima de combustíveis fósseis. $\mathrm{O}$ uso de combustíveis tradicionais, no entanto, está associado a um aumento ambiental na intensidade de gases nocivos, como dióxido de carbono, gases de efeito estufa e óxido de nitrogênio.

A maioria dos países ainda está usando combustíveis tradicionais como principal fonte de energia. Os impactos negativos da queima de combustíveis fósseis foram reconhecidos em todo o mundo, e a busca por fontes alternativas de combustível já começou. Vários países mudaram sua prioridade para fornecimento de energia de recursos não renováveis para recursos renováveis. Apenas algumas fontes de energia, porém, são sustentáveis e têm menor impacto ambiental. O uso de "culturas de bioenergia" para geração de energia é uma dessas alternativas em potencial, com resultados positivos a longo prazo. A energia das culturas de bioenergia é obtida a partir de biomassa derivada de plantas e animais, gerando produtos como etanol, biodiesel, biogás, etc. que reduzem o nível de dióxido de carbono, diminuem a emissão de gases de efeito estufa, aumentam o carbono do solo, reduzem a erosão, aumentam a transpiração e podem fornecer calor e eletricidade. Além disso, podem remediar o solo contaminado por metais pesados (GRESSHOFF et al., 2017; YADAV et al., 2019).

Depois de passar muitas décadas desfrutando de uma crescente exploração dos campos de carvão, gás e petróleo, as mudanças climáticas e a vulnerabilidade derivada do esgotamento gradual dos recursos fósseis, juntamente com uma crescente demanda por energia, causaram às administrações de muitos países a necessidade de adoção de medidas para diversificar as fontes de energia e mitigar esses impactos negativos. A demanda global de biocombustíveis aumentou significativamente na última década e espera-se que aumente, ainda mais, na próxima. Fontes alternativas de energia, que substituem as reservas de recursos fósseis em declínio contínuo, foram desenvolvidas e usadas cada vez mais. Os biocombustíveis líquidos, sólidos e gasosos ganharam particular relevância em virtude de seu fácil uso em aquecimento, geração de energia, veículos e motores de combustão interna sem modificações relevantes. A última década também foi caracterizada pela busca e exploração de novas fontes convencionais de energia, e atualmente estamos com um excesso de oferta juntamente com reduções de preços. Apesar desse cenário atual, os fundamentos que sustentam a racionalidade e a conveniência de desenvolver fontes alternativas, como a bioenergia, continuam em vigor (ARNDT; HENLEY; HARTLEY., 2019; HILBERT; GALLIGANI, 2015).

O objetivo do presente trabalho consiste na conexão, sob uma perspectiva essencialmente teórica, de certas questões específicas que dizem respeito (1) ao apelo socioeconômico; (2) ao processo de mudança na perspectiva institucional e (3) à ação empreendedora dirigida aos processos de estruturação de determinadas configurações produtivas ligadas à bioenergia no Brasil. No corpo do texto serão levantados elementos-chave associados a esses processos de estruturação, na medida em que, na prática das relações socioeconômicas, tendem a estimular o emprego e a institucionalização de formas alternativas de produção e uso da bioenergia. Destaca-se a ação desencadeada pelos empreendedores como promotores desses processos, com vistas à sedimentação de práticas que possam vir a estar vinculadas à filosofia do desenvolvimento sustentável e/ou das chamadas inovações sociais. 
O APELO SOCIOECONÔMICO E A AÇÃO EMPREENDEDORA NO PROCESSO DE ESTRUTURAÇÃO DE CONFIGURAÇÕES PRODUTIVAS VINCULADAS À BIOENERGIA NO BRASIL

Fábio Freitas Schilling Marquesan - Joselito Brilhante Silva

O percurso metodológico deste trabalho tem caráter ensaístico, que consiste em conectar, sob uma perspectiva essencialmente teórica, determinadas questões que vinculem o apelo socioeconômico à figura do empreendedor como promotor da mudança nos processos de estruturação das configurações produtivas relacionadas à produção de bioenergia no Brasil. Para tanto, foram levantados alguns elementos relacionados à estruturação de campos organizacionais e que se referem, também, aos processos de institucionalização, ao modo pelo qual os atores, com destaque à figura do empreendedor institucional, conduzem essas inovações sociais no campo da atuação prática, e à reestruturação de antigas estruturas destinadas a abarcarem questões de cunho socioambiental.

Sem, porém, se ater tanto aos aspectos técnicos da produção, tampouco à solução dos problemas estruturais do setor, busca-se levantar como ocorrem os processos de estruturação dos campos organizacionais que tendem a estimular o uso de fontes e formas alternativas de produção de bioenergia no Brasil. No desenrolar do texto são discutidas, brevemente, as etapas de uma proposta teórica de institucionalização que, por mais rudimentar que possa parecer, dá uma ideia de como, por meio de ações orientadas à mudança social, podem se alcançar diferentes configurações produtivas. Em seguida, atenta-se para o trabalho do empreendedor como agente da referida mudança institucional. Antes será feita uma breve apreciação quanto ao chamado apelo socioeconômico da produção bioenergética.

\section{O APELO SOCIOECONÔMICO DA PRODUÇÃO BIOENERGÉTICA NO BRASIL}

Convém salientar dois aspectos relevantes à produção de bioenergia no Brasil. O primeiro diz respeito ao enorme potencial produtivo do país, com especial destaque ao setor econômico, constituído pela produção e comercialização da cana-de-açúcar. A presença de tal estrutura produtiva encontra-se fortemente institucionalizada na sociedade desde os primórdios da colonização europeia, nas primeiras plantações instaladas em solo brasileiro (em São Vicente e Pernambuco). Afora essas raízes históricas, a indústria da cana no Brasil dispõe de parque fabril bem estruturado e distribuído em diversos polos de produção situados em diferentes regiões do país e, ainda, conta a seu favor com políticas públicas que, desde meados dos anos 1970 (motivadas, principalmente, pela crise do petróleo de 1973), impulsionam o desenvolvimento de tecnologias capazes de prover, por exemplo, toda uma frota veicular adaptada ao uso do etanol - algo que, no cenário internacional, é absolutamente sui generis. Da cana, até o bagaço pode ser usado para a produção de energia elétrica, um potencial energético ainda pouco explorado no país.

Ademais, o Brasil possui dimensões continentais e grande diversidade geográfica e climática, o que garante boas condições de cultivo de quase todos os produtos agrícolas de interesse comercial no mundo. $\mathrm{O}$ segundo aspecto responde, portanto, justamente pelo poderio geopolítico internacional que esse tipo de vantagem estratégica concede ao Brasil, o que, invariavelmente, e, mesmo que, por ventura, não de modo intencional, intimida outras potências. Prova desse jogo de interesses são as frequentes associações veiculadas na imprensa internacional da imagem do país com relação a falácias, por exemplo, de que a produção bioenergética nacional esteja prejudicando a disponibilidade, bem como, contribuindo para o aumento do preço dos alimentos nas bolsas de commodities internacionais - vide a pressão internacional e a assimetria de informações que se instalou no mundo quando da crise de fornecimento de alimentos aos países asiáticos e africanos em meados de 2008. 
O APELO SOCIOECONÔMICO E A AÇÃO EMPREENDEDORA NO PROCESSO DE ESTRUTURAÇÃO DE CONFIGURAÇÕES PRODUTIVAS VINCULADAS À BIOENERGIA NO BRASIL

Fábio Freitas Schilling Marquesan - Joselito Brilhante Silva

Aliada ao argumento de que há uma ameaça à produção de alimentos, tem-se a preocupação sobre o aumento da exploração de monoculturas e de trabalhadores rurais na disputa por uma maior produção em relação aos países industrializados, o que beneficiaria companhias multinacionais. Se, por um lado, a produção de bioenergia no Brasil é, hoje, perfeitamente passível de coexistência junto àquela destinada à produção de alimentos, sem maiores prejuízos para qualquer um dos lados, por outro ainda há muito a ser feito a fim de melhorar a competitividade (restrita à questão econômica) e a sustentabilidade (tomada em sentido amplo) dessa indústria. Em outros termos, não é por conta da produção de álcool que existem os problemas de abastecimento e/ou má distribuição de alimentos no mundo, embora se tenha a consciência de que, de fato, a produção bioenergética, da forma como está estruturada, comprometa, sem sombra de dúvidas, algumas das dimensões de uma proposta mais ampla de desenvolvimento sustentável.

A produção de cana-de-açúcar no Brasil é oriunda, em sua maioria, de grandes fazendas que empregam cada vez menos funcionários, sendo inúmeros os casos anualmente registrados de exploração e de más condições de trabalho. Nas áreas de relevo acidentado, que constituem uma parcela significativa da área total cultivada, a prática da queima da palhada no fim dos meses de inverno ainda é bastante comum. A justificativa para essa atitude parte do entendimento de que isso facilita a colheita (sob o ponto de vista dos trabalhadores braçais, principalmente) no sentido de que proporciona maior segurança e melhores condições de trabalho, uma vez que os campos ficam mais limpos. Por outro lado, a queima da palhada agrava os efeitos nocivos da produção monocultural (principalmente, quanto à estrutura física, química, biológica e microbiológica do solo), aumenta os índices de poluição nas cidades vizinhas às plantações e, ainda, contribui para a emissão de carbono na atmosfera.

Em relação ao biodiesel produzido a partir da soja, o dispêndio energético consumido em sua elaboração (passando pelas etapas de extração bruta e refino), apesar de toda a tecnologia envolvida, ainda é maior do que a capacidade de fornecimento de energia a partir do grão. Com os métodos disponíveis hoje, o custo energético da extração supera aquilo que a oleaginosa pode oferecer, ou seja, dado o balanço energético negativo do processo, não compensa produzir biodiesel a partir de soja - a principal cultura agrícola do país. Outro aspecto relacionado à produção de soja é o baixo número de pessoas que são requeridas para trabalhar em cada hectare produzido, o que lhe dá pouco apelo social em projetos de bioenergia.

De qualquer modo, e, sem desmerecê-la, a solução dessas questões vai além das questões eminentemente técnicas. É evidente que ela passa por avanços tecnológicos que ofereçam alternativas, por exemplo, à queima da palha antes da colheita da cana e que deem viabilidade ao uso da soja como matéria-prima para a produção de biodiesel. Passa, também, pela efetivação de projetos que priorizem a criação de empregos nos quais os trabalhadores possam vir a ser agentes legítimos de transformação social, ao invés de engrossarem a massa daqueles sem maiores perspectivas sociais. A solução desses problemas passa, ainda, pela institucionalização da produção e beneficiamento de fontes alternativas a essas duas culturas para a produção de bioenergia, o que já vem sendo feito, mesmo que de modo insuficiente.

Pensa-se igualmente na integração de usinas de álcool e de biodiesel a fim de reduzir os custos, posto que o álcool é usado para a reação que resulta no biodiesel e no aproveitando das plantações de cana-de-açúcar em alternância ao plantio de oleaginosas, usando, assim, os 
O APELO SOCIOECONÔMICO E A AÇÃO EMPREENDEDORA NO PROCESSO DE ESTRUTURAÇÃO DE CONFIGURAÇÕES PRODUTIVAS VINCULADAS À BIOENERGIA NO BRASIL

Fábio Freitas Schilling Marquesan - Joselito Brilhante Silva

mesmos trabalhadores, sistemas e modelos de gestão. $\mathrm{O}$ óleo pode ser produzido a partir da energia gerada com a produção de açúcar e de álcool, podendo produzir um impacto no custo final do biodiesel.

A fundamentação desta seção tem por base o trabalho de Domac, Richards e Rosovic (2005), que se propuseram a revisar os aspectos socioeconômicos da produção de bioenergia em países em desenvolvimento, estando entre estes o Brasil, segundo a classificação dos autores. Entre os achados vinculados à dimensão social daquele trabalho, consta que determinados fatores, como a educação, a preservação do meio ambiente e o cuidado com a saúde, já constituem elementos que se equivalem aos tradicionais padrões de consumo ou níveis de renda, como componentes básicos do conceito internacional de padrão de vida. Não basta, pois, que determinados espaços sociais ocupados por algum tipo de atividade econômica se caracterizem pela capacidade de geração de capital financeiro.

Nesse sentido, a execução de projetos de bioenergia em regiões marginalizadas, por exemplo, mesmo que venha a contribuir positivamente para a percepção de que esteja havendo períodos de maior estabilidade social (por conta, por exemplo, da amenização do êxodo rural em regiões com baixas oportunidades de emprego), pode não ser suficiente para promover uma transformação social significativa; isto, se não vier acompanhada de mudanças em outras esferas que constituem a conjuntura sociopolítico-econômica de um dado território, bem como os indicadores que compõem o padrão de vida.

Ao se referirem aos chamados efeitos macroeconômicos atrelados aos projetos de bioenergia, Domac, Richards e Rosovic (2005) ressaltam a tendência destes em contribuir para as políticas nacionais de substituição das importações, com vistas à maior seguridade e diversificação das fontes energéticas à disposição de uma região. Os autores ponderam que tais empreendimentos seriam ideais para o aquecimento de economias locais, pois tendem a gerar mais empregos em comparação às fontes não renováveis de produção de energia, intensivas em capital. Afirmam eles, entretanto, que, afora a primazia das variáveis de caráter geopolítico e das macroestratégias de desenvolvimento internacionais, obstáculos econômicos à sua maior expansão ocorrem basicamente porque os mercados não reconhecem os custos reais, tampouco os riscos atrelados à exploração intensiva de combustíveis fósseis e nucleares.

Quanto aos combustíveis fósseis, ao serem queimados liberam dióxido de carbono, principal responsável pelo aumento do efeito estufa, e, em relação a isso, ainda espera-se que os países industrializados atendam ao chamado constante no Protocolo de Kyoto para que reduzam seus níveis de emissões (5,2\% em relação ao ano de 1999). Não parece haver, porém, um empenho na mudança nos padrões de consumo nesses países, com reduções não efetivas, e, sim, arranjos, como o Clean Development Mechanism (CDM). Para garantir que os países em desenvolvimento também possam se desenvolver de maneira sustentável, o Acordo de Paris baseia-se no Protocolo de Kyoto na medida em que compromete os países desenvolvidos a apoiar os países em desenvolvimento com ajuda monetária e tecnológica para adquirir tecnologias limpas. Por meio dos Mecanismos de Desenvolvimento Limpo, busca-se reduzir emissões e alcançar o desenvolvimento sustentável. O fundamento para sua proposição foi de que apenas mecanismos de mercado levariam à redução das emissões de modo eficiente a um custo efetivo (MISOCZKY; BÖHM, 2012; VENEMA, 2018). 
O APELO SOCIOECONÔMICO E A AÇÃO EMPREENDEDORA NO PROCESSO DE ESTRUTURAÇÃO DE CONFIGURAÇÕES PRODUTIVAS VINCULADAS À BIOENERGIA NO BRASIL

Fábio Freitas Schilling Marquesan - Joselito Brilhante Silva

Há, todavia, os que defendem essa postura, com vários programas em andamento no Brasil, chamados de "projetos de créditos de carbono" ou "projetos de MDL" (sigla em português para $(D M)$, alegando que a permissão à entrada de recursos externos ao país contribui para a sustentabilidade ambiental e gera emprego e renda à população, promovendo a interiorização do desenvolvimento na busca de redução das disparidades regionais e sociais.

Os contrários a isso reforçam que esse cenário não tem nada de sustentável, mas, sim, um caráter oportunista: o vislumbre de possibilidades vantajosas em novas fontes de negócios e não a mudança de hábitos de consumo, e a produção de bilhões de litros de combustíveis alternativos em compensação à pequena redução dos combustiveis fósseis (CASSOL, 2007). De qualquer modo, asseguram Domac, Richards e Rosovic (2005), as mudanças ou, pelo menos, a ameaça de alterações no clima global, junto a acordos internacionais visando o corte das emissões de carbono, têm encorajado cada vez mais o uso da bioenergia, que tende a se expandir principalmente em regiões que, até então, foram menos favorecidas pelos fluxos internacionais de capitais. Nesse processo, sustentam eles, acabam sendo gerados empregos diretos e indiretos tanto nos campos de produção quanto na construção e na manutenção de plantas industriais, além daqueles no transporte da biomassa e demais atividades de caráter auxiliar. A questão do encorajamento é em relação ao esgotamento progressivo das fontes fósseis de energia, não pelo clima ou acordos.

Entre as conclusões daquele estudo, destaca-se o potencial da indústria da bioenergia, como tecnologia intensiva em trabalho, e que gera empregos em âmbito local, regional e nacional. Essa propensão à geração de empregos depende, porém, como advertem Domac, Richards e Rosovic (2005), de certos fatores específicos, como: 1) as etapas do ciclo da produção de energia que estão em questão ou à disposição de determinada região (se produção, conversão ou distribuição); 2) as condições gerais do processo envolvido na conversão dessa energia (disponibilidade de plantas industriais e insumos para a produção de energia); 3) a configuração ou arranjo econômico-produtivo específico de cada local (países em desenvolvimento, sistema produtivo tradicional, mão de obra informal versus países desenvolvidos, sistema produtivo modernizado, mão de obra subsidiada ou formalizada); 4) a produção ser mecanizada ou intensiva em trabalho; e 5) a escala dos projetos (propostas de grandes dimensões tendem a empregar menos pessoas do que as de pequenas).

Retornando à questão dos componentes básicos do conceito internacional de padrão de vida, identificou-se, por meio daquele trabalho, que muitos países em desenvolvimento ainda exploram a bioenergia de modo tradicional, fato que, em virtude do crescimento populacional, basicamente acaba pressionando os recursos naturais além da sua capacidade regenerativa. Tal conclusão, entretanto, parece ser um tanto simplória, dada a plêiade de outros fatores, os quais contribuem para que fatores como a educação, a preservação do meio ambiente e o cuidado com a saúde estejam deteriorados em países emergentes - e, inclusive, sendo agravados, justamente por conta de explorações de cunho bioenergético que não levam em consideração o apelo socioambiental.

Encerrando a série de considerações socioambientais levantadas em Domac, Richards e Rosovic (2005), tem-se o dado de que os países desenvolvidos investem mais em pesquisa e desenvolvimento ( $P \& D)$ do que aqueles em desenvolvimento, e estimulam o uso da bioenergia em seus territórios em razão da questão da seguridade energética e da aposta em seus benefícios 
O APELO SOCIOECONÔMICO E A AÇÃO EMPREENDEDORA NO PROCESSO DE ESTRUTURAÇÃO DE CONFIGURAÇÕES PRODUTIVAS VINCULADAS À BIOENERGIA NO BRASIL

Fábio Freitas Schilling Marquesan - Joselito Brilhante Silva

ambientais superiores a outras fontes. Em termos operacionais, afora a baixa competitividade em custos (que pode ser compensada por subsídios), há uma série de barreiras socioeconômicas e institucionais que precisam ser superadas; mesmo assim, o custo do investimento por emprego criado no setor da bioenergia é menor do que a média daqueles estimados em projetos dirigidos às indústrias petroquímica e hidrelétrica.

Assim, esta primeira seção teve por propósito amarrar a discussão eminentemente teórica que se irá empreender, no corpo do texto, a um campo empírico específico - o da produção de bioenergia no Brasil. Daqui em diante, a argumentação passa por mais duas seções teórico-conceituais, para, então, retornar à apreciação do que se chamou de campo empírico nas considerações finais. As transformações sociais em curso envolvem elementos outros que não somente aqueles vinculados a aspectos de natureza técnica. $O$ que está em voga no âmbito do ambiente institucional exerce influência nessa conjuntura e sobre as transformações nesse ambiente, o que trata a seção seguinte.

\section{O PROCESSO DE MUDANÇA NA PERSPECTIVA INSTITUCIONAL}

A presente seção traz como mote a lógica dos chamados processos de institucionalização, baseados numa corrente específica da Teoria Institucional em que se enaltece a mudança nos arranjos estruturais das organizações. Tal argumentação desencadeia-se a partir de uma questão pertinente levantada por Tolbert e Zucker (2006). Elas mostram que, a despeito do considerável volume de trabalhos reunidos sob o título de Teoria Institucional, pouca atenção tem-se dado à conceitualização e/ou à especificação do processo de institucionalização como variável dependente nas análises organizacionais. Tolbert e Zucker (2006, p. 203), resgatam, então, um conjunto de "processos sequenciais" inerentes ao fenômeno, que culmina com a etapa de sedimentação, isto é, a institucionalização total.

Convém salientar a advertência de Machado-da-Silva e Gonçalves (2006), segundo os quais, naquilo que diz respeito à compreensão da dinâmica dos fenômenos sociais, os três momentos da mudança (habitualização, objetificação e sedimentação), levantados por Tolbert e Zucker (2006), não devem ser imaginados como se ocorressem em uma sequência temporal. Ao contrário, dizem eles, referindo-se ao trabalho de Berger e Luckmann (1979), a sociedade e cada uma de suas partes constituintes são e estão, simultaneamente, ou seja, a todo o momento, caracterizadas por estes três momentos, de tal modo que qualquer análise que considere apenas um ou dois deles, é insuficiente para se compreender o todo.

Conforme diagnóstico exibido em trabalho anterior (ZUCKER, 1977), a institucionalização pode aparecer tanto como processo quanto como variável-atributo. A importância de se resgatar tal ponto está no fato de que, nas análises organizacionais, a institucionalização é quase sempre tratada como um estado qualitativo, ou seja, as estruturas são/estão institucionalizadas ou não (TOLBERT; ZUCKER, 2006). Isso vai ao encontro do raciocínio defendido anteriormente, isto é, a institucionalização não costuma ser posicionada no lugar da variável dependente. Consequentemente, negligenciam-se importantes questões tanto em relação aos fatores determinantes quanto sobre as consequências de possíveis níveis de institucionalização diferenciados, bem como sobre como tais variações podem afetar o grau de similaridade entre conjuntos de organizações (TOLBERT; ZUCKER, 2006) ou campos em estruturação - numa alusão aos mecanismos de isomorfismo institucional (DIMAGGIO; POWELL, 2000). 
O APELO SOCIOECONÔMICO E A AÇÃO EMPREENDEDORA NO PROCESSO DE ESTRUTURAÇÃO DE CONFIGURAÇÕES PRODUTIVAS VINCULADAS À BIOENERGIA NO BRASIL

Fábio Freitas Schilling Marquesan - Joselito Brilhante Silva

Tendo por base o trabalho de Berger e Luckmann (1979), então dirigido à verificação da ocorrência de processos de institucionalização entre atores individuais e não organizacionais, Tolbert e Zucker (2006) propõem que as organizações, como entes socialmente construídos, devam desenvolver alguma forma de categorização (ou tipificação) quanto aos seus diversos tipos de intercâmbio. Ao percorrer uma cadeia processual de eventos, essas categorizações podem vir a alcançar a condição de objetificadas e, nessa situação, tendem a se constituir na própria realidade institucionalizada, ou seja, passam a ser socialmente compartilhadas pelos agentes que nelas atuam. As organizações, pelo menos inicialmente, comportam-se em acordo com esse processo, posto que, em optando por tal caminho, tanto a ambiguidade quanto a incerteza relativa à conduta social dos agentes em relação à ação social dos demais, acaba por ser reduzida.

Apoiados no trabalho de Schutz (1962), Berger e Luckmann (1979) definem, em tom categórico, uma instituição como o resultado ou o estágio final de um processo de institucionalização. Em tal perspectiva, é justamente esse o processo que constitui o ponto central da análise organizacional. $O$ referido processo é pautado por uma tipificação de ações que são tornadas habituais a um grupo por intermédio de atores específicos - o que abarca o desenvolvimento recíproco de definições ou significados compartilhados que estão ligados àqueles comportamentos que foram tornados habituais. Em outras palavras, tais ações (tornadas habituais) referem-se a comportamentos que foram adotados numa dada organização a fim de resolver determinados problemas que, por algum motivo qualquer, se tornaram, em certo momento, recorrentes.

Tentando delinear uma explicação para o suposto encadeamento de atividades que tenderia a ocorrer em um contexto organizacional, Tolbert e Zucker (2006) sustentam que o subprocesso de habitualização encerra (1) o conjunto de comportamentos padronizados e dirigidos à solução de problemas específicos; e (2) a associação desses comportamentos a certos estímulos processuais particulares que ocorreriam simultaneamente. Isso envolveria, por conseguinte, a geração de diferentes arranjos estruturais, como também a formalização desses arranjos em políticas e procedimentos próprios a uma dada organização, ou, de modo análogo, a um conjunto de organizações que, por ventura, enfrentassem problemas semelhantes. $O$ desenrolar desses processos tende a resultar em um conjunto de estruturas, ainda em suspensão, que pode estar ocupando alguma posição no estágio de pré-institucionalização.

O subprocesso de objetificação, por outro lado, refere-se à generalização dos significados atribuídos a uma dada ação que foi tornada habitual por uma coletividade. A significação torna-se socialmente compartilhada e o comportamento dos agentes comum, independentemente da ação individual daqueles agentes que, por hipótese, teriam o poder de interferir nesse modus operandis de forma mais incisiva, se motivados por interesses particulares e/ou quando dotados dos recursos adequados (DIMAGGIO, 1988). O movimento em direção a um status de permanência e tendente à disseminação, baseia-se nessa ideia de objetivação que acompanha a difusão de uma estrutura particular para além dos atores enquanto tomados como unidades individuais. Esse processo envolve e depende, também, do desenvolvimento de certo grau de consenso social entre aqueles munidos do poder de decidir ou deliberar no interior de uma organização, a respeito da potencial adoção, ou não, de uma estrutura diferente. Isto se dá, nessa abordagem, com base em tratativas de consenso e negociação. 
O APELO SOCIOECONÔMICO E A AÇÃO EMPREENDEDORA NO PROCESSO DE ESTRUTURAÇÃO DE CONFIGURAÇÕES PRODUTIVAS VINCULADAS À BIOENERGIA NO BRASIL

Fábio Freitas Schilling Marquesan - Joselito Brilhante Silva

Tal consenso pode emergir por meio de dois mecanismos diferentes, embora não necessariamente não relacionados. Por um lado, a objetivação da estrutura é, em parte, consequência do monitoramento que a organização faz dos competidores e de esforços para aumentar sua competitividade relativa. Por outro, envolve duas grandes tarefas de teorização: (1) a definição ou especificação de um problema organizacional genérico, para o qual uma inovação local representa uma solução ou tratamento; e (2) a justificativa para a adoção dessa inovação. O ímpeto para a difusão, nesse estágio, deixa de ser a simples imitação, para, então, adquirir uma base mais normativa, refletindo a teorização das estruturas e, à medida que a teorização se desenvolve e se explicita, tende a diminuir a variação na forma que as estruturas tomam em diferentes organizações (TOLBERT; ZUCKER, 2006).

O subprocesso de sedimentação, por fim, diz respeito àquele por meio do qual as ações adquirem a qualidade de exterioridade. Tal propriedade refere-se ao grau em que as tipificações são "vivenciadas como possuindo uma realidade própria, que confronta o indivíduo como um fato externo e coercitivo" (BERGER; LUCKMANN, 1979, p. 58). Ela está relacionada à continuidade histórica das tipificações (ZUCKER, 1977) e, em particular, à transmissão das tipificações aos novos membros que, não tendo conhecimento das suas origens, estão aptos a tratá-las como dados sociais incontestes (BERGER; LUCKMANN, 1979; ZUCKER, 1977).

Nesse estágio, a propensão dos atores para empreender avaliações independentes da estrutura tende a declinar de modo significativo. A institucionalização total envolve, pois, um processo que se apoia fundamentalmente na continuidade histórica da estrutura e, especialmente, em sua sobrevivência pelas várias gerações de membros da organização. A sedimentação caracteriza-se tanto pela propagação virtualmente completa de suas estruturas quanto pela reprodução das mesmas por um período consideravelmente longo de tempo. Deste modo, tal processo implica bidimensionalidade (largura e profundidade) das estruturas (EISENHARDT, 1988).

A identificação dos fatores que afetam a abrangência do processo de difusão, como também a conservação, a longo prazo, de uma estrutura, passa a ser, então, a chave para a compreensão do processo de sedimentação. A total institucionalização da estrutura depende, portanto, dos efeitos conjuntos de: (1) uma relativa baixa resistência de grupos de oposição; (2) uma promoção e apoio cultural continuado pelos grupos de defensores; e, (3) uma correlação positiva com resultados desejados.

O entendimento reciprocamente compartilhado dessas práticas permite intercâmbios ordenados e, ao longo do tempo, tal entrosamento (baseado em crenças coletivas) torna-se reforçado por processos regulatórios. Essa normatização pode envolver agências ligadas ao Estado e/ ou entidades profissionais que, de modo normativo e/ou coercitivo, imprimem conformidade às comunidades organizacionais imersas nessas normas. Processos regulatórios disseminam e reproduzem prescrições codificadas da realidade social, considerando que desvios dessas prescrições tendem a causar desconforto, o que desencadeia tentativas de justificação (ou legitimação) quanto ao potencial abandono das normas sociais vigentes (GREENWOOD; SUDDABY; HININGS, 2002). 
O APELO SOCIOECONÔMICO E A AÇÃO EMPREENDEDORA NO PROCESSO DE ESTRUTURAÇÃO DE CONFIGURAÇÕES PRODUTIVAS VINCULADAS À BIOENERGIA NO BRASIL

Fábio Freitas Schilling Marquesan - Joselito Brilhante Silva

\section{O EMPREENDEDOR COMO AGENTE DE MUDANÇAS INSTITUCIONAIS E INOVAÇÕES SOCIAIS}

Nesta seção, conduz-se a discussão para a apreciação da ação empreendedora, especificamente no que diz respeito à atuação do empreendedor como agente causal dos processos de institucionalização. Para os fins deste trabalho, o empreendedor é entendido como sendo aquele agente capaz de desencadear a mudança institucional com vistas à introdução de inovações sociais e desafiando as potenciais restrições à ação por parte daqueles que se encontram imersos em estruturas ditadas por comportamentos institucionalizados.

Da síntese conceitual obtida em Scott (2007), depura-se que as instituições sejam estruturas multifacetadas que enaltecem a presença de elementos simbólicos na constituição dos arranjos organizacionais, mas que somente alcançam significância e/ou legitimidade social na medida em que estejam conectadas a agentes capazes de mobilizar recursos materiais, que são os empreendedores institucionais (DIMAGGIO, 1988). Os estudos vinculados à temática do empreendedorismo institucional dirigem-se, pois, à investigação do comportamento de atores socialmente organizados e dotados, justamente, dessa capacidade de mobilização de recursos, de forma tal que os permitam contribuir tanto na formação quanto na mudança dos campos organizacionais que, por ventura, já estejam sedimentados, para usar a nomenclatura de Tolbert e Zucker (2006).

Caracterizam-se tais empreendedores, ainda, por serem aqueles dotados de competência e/ou legitimidade para introduzir inovações (sociais) nos campos organizacionais, estimulando, assim, a promoção de novas instituições, transformando os arranjos existentes e já institucionalizados, além de inserirem novas e diferentes práticas e sentidos para a ação social. Não obstante, a mudança institucional plena demanda a ação de agentes capazes não somente de desafiar práticas sociais estabelecidas, mas de rompê-las, ainda que as rotinas previamente sedimentadas continuem sendo seguidas e consideradas certas e imutáveis por parte dos atores que ainda não tenham adotado a inovação.

Com isso em mente, cabe recuperar o argumento de Silverman (1970), que se opunha ao gerencialismo da teoria organizacional formal e acentuava a natureza socialmente construída das organizações, alinhando-as ao tema da mudança social. Uma vez que as organizações são criações humanas ao invés de entidades naturais, portanto, elas são passíveis de serem transformadas mediante a intervenção social liderada pelos empreendedores institucionais (MARSDEN; TOWNLEY, 2006). Atribui-se, portanto, a responsabilidade pela mudança nos campos organizacionais à ação coordenada por esse tipo de agente (HARDY; MAGUIRE, 2008).

A relação entre empreendedorismo e mudança é antiga e vem sendo investigada há praticamente um século. Quem primeiro dedicou atenção à figura do empreendedor como agente promotor de mudanças e inovações com envergadura para alterar a dinâmica de uma instituição como o mercado, por exemplo, foi o economista Joseph Schumpeter. Inicialmente, em 1912, Schumpeter associou-o à figura de um indivíduo em posição de liderança e, posteriormente, em 1934, vinculou esse papel aos departamentos de pesquisa e desenvolvimento (P\&D) dentro das organizações com ímpeto inovador. Essa abordagem, que associa empreendedorismo e inovação, atrela, de forma inequívoca, a ação dos empreendedores à mudança, posto que seriam eles os responsáveis pelo processo consagrado por Schumpeter sob o desígnio de "destruição-criadora", em que, numa economia capitalista, o novo, o diferente, o inovador, invariavelmente 
O APELO SOCIOECONÔMICO E A AÇÃO EMPREENDEDORA NO PROCESSO DE ESTRUTURAÇÃO DE CONFIGURAÇÕES PRODUTIVAS VINCULADAS À BIOENERGIA NO BRASIL

Fábio Freitas Schilling Marquesan - Joselito Brilhante Silva

suplanta o velho, ocupando seu lugar. A importância do empreendedor (ou grupo, ou organização empreendedora) nessa dinâmica econômica está no estímulo ao desenvolvimento que é dado por essa figura, em virtude de sua capacidade de fazer coisas novas e melhores (FILION, 1999; LÉVESQUE, 2004).

A geração de valor, que é tradicionalmente associada ao trabalho de um empreendedor, costuma ser representada em termos de valor econômico. Por meio desse, torna-se possível a uma organização, por exemplo, obter certa legitimidade num dado ambiente, uma vez que consiga apresentar determinado nível de lucratividade econômico-financeira "aceitável" para aquele espaço de relações socioeconômicas em particular. Contestam, no entanto, Peredo e McLean (2006) e Murphy e Coombes (2009), que, cada vez mais, uma forma diferente de criação de valor vem se destacando como um poderoso mecanismo de desenvolvimento social, oferecendo possibilidades mais amplas às sociedades, indo além daquelas vinculadas tão somente ao aspecto econômico-financeiro.

Em relação ao que hoje se entende por empreendedor social, destaca-se a sua capacidade de condução das organizações ou dos campos organizacionais em vias de mudança à geração e/ou incorporação das chamadas inovações sociais (BRUNSTEIN; RODRIGUES; KIRSCHBAUM., 2008). Esse tipo de inovação, na visão dos referidos autores, difere daquele consagrado pelo conceito econômico-schumpeteriano, pois vincula a finalidade da mesma ao aspecto social ao invés do financeiro. Existe uma série de ações sociais cujo objetivo destina-se à melhoria dos aspectos sociais, como a qualidade de vida da sociedade em geral, que estão sendo enquadradas sob o rótulo de inovações, mas que não estão, necessariamente, relacionadas à expectativa de retornos financeiros diretos por parte daqueles que as propõem (POL; VILLE, 2009).

Mesmo não havendo, ainda, consenso acerca do que os teóricos agrupam ou classificam sob a denominação de inovações sociais, o que se apura é a constante alusão às transformações sociais que visam à satisfação das necessidades humanas, tomadas em sentido genérico. Essa temática é relativamente recente e, ao se explorar o trabalho de Cloutier (2003), constata-se que os primeiros autores a usarem o termo "inovação social", da forma como se o concebe hoje, foram Taylor (1970) e Gabor (1970).

Ampliando o escopo do conceito, Phills, Deiglmeier e Miller (2008) admitem que as inovações sociais, no campo organizacional, apontam para a busca de novas soluções para determinados problemas sociais de modo que o resultado dessas ações seja mais efetivo, mais eficiente e mais sustentável do que as propostas existentes e pela qual o valor criado seja revertido para a sociedade como um todo, em vez de ser dirigido apenas a fins particulares. Em outras palavras, por meio das inovações sociais, os empreendedores promovem rearranjos nas configurações sociais, além de darem respostas apropriadas para situações sociais insatisfatórias e problemáticas.

Com o intuito de selar o entendimento sobre o que constitui uma inovação social para os fins do presente ensaio, exibe-se o posicionamento adotado pelo Centre de Recherche sur les Innovations Sociales (Crises), grupo de estudos canadense sediado em Montreal, Canadá, e que sugere o seguinte: as inovações sociais representam um processo iniciado pelos atores sociais para responder a uma aspiração de suprir uma necessidade, uma solução ou aproveitar uma oportunidade de ação para mudar as relações sociais, transformando um quadro ou propondo novas orientações culturais. Ao combinar as inovações pode-se ter grande eficiência no 
O APELO SOCIOECONÔMICO E A AÇÃO EMPREENDEDORA NO PROCESSO DE ESTRUTURAÇÃO DE CONFIGURAÇÕES PRODUTIVAS VINCULADAS À BIOENERGIA NO BRASIL

Fábio Freitas Schilling Marquesan - Joselito Brilhante Silva

termo social, excedendo o projeto original (empresas, associações, etc.). As inovações sociais se tornam uma fonte de transformação social e podem contribuir para o surgimento de novos modelos de desenvolvimento e uma série de processos desencadeados pelos diferentes atores que compõem um dado tecido social, na intenção de oferecer respostas a alguma aspiração humana, suprir uma necessidade, trazer uma solução ou aproveitar uma oportunidade de ação socialmente coordenada, na intenção de mudar a dinâmica das relações sociais, de transformar uma realidade que não seja favorável à equidade social, ou de propor novas orientações culturais a uma coletividade (VAILLANCOURT, 2008).

Mesmo que os empreendedores institucionais possam assumir configurações variadas, o que inclui ações desenvolvidas em âmbito individual, organizacional, em redes ou, até mesmo, envolvendo movimentos que aspiram à inovação de cunho social, há forte relação entre esse tipo de ação e aquele realizado por empreendedores sociais e/ou coletivos (HARDY; MAGUIRE, 2008). O empreendedor institucional tem características políticas e sociais peculiares, o que lhe permite agir com engajamento em questões sociais mais amplas, almejar a promoção de mudanças nas relações entre atores e provocar o desencadeamento de ações de caráter social e coletivo.

Independentemente do modo de atuação, se de forma isolada ou coletiva, se com vistas a objetivos particulares ou sociais, uma das primeiras e mais importantes questões que se coloca na discussão sobre empreendedorismo institucional está relacionada ao que a literatura especializada identifica como sendo o paradoxo da imersão (LECA; BATTILANA; BOXENBAUM, 2008), uma vez que, assim como os demais atores, os empreendedores (de qualquer tipo) também se encontram, em dado momento, imersos no ambiente institucional circundante. Torna-se um desafio à Teoria Institucional elaborar uma explicação plausível quanto à capacidade de reflexão e predisposição à mudança por parte desses agentes.

Os empreendedores, assim como os demais atores que constituem um campo, encontram-se sujeitos às mesmas tensões regulatórias, normativas e cultural-cognitivas que tendem a orientar o comportamento dos indivíduos numa coletividade. Também é difícil explicitar, dadas as peculiaridades da teoria, o modo pelo qual os empreendedores conseguem fazer com que os outros atores, também imersos, aceitem e incorporem as novas práticas sociais (BARATTER; FERREIRA, J. M.; COSTA, 2009).

Como os atores encontram-se sempre imersos num dado padrão institucional vigorante, as possibilidades de mudança acabam sendo limitadas. As alternativas são restritas, basicamente, porque os atores imersos exibem certa dificuldade na concepção de escolhas estratégicas posicionadas fora daquilo que é dado como certo porque elas se mostrariam inaptas diante de um repertório de opções tido como já sedimentado (BARATTER; FERREIRA; COSTA, 2009).

Por meio da construção e manutenção de identidades sociais os indivíduos elaboram a personalidade que provê uma base individual e independente para a ação em determinadas situações sociais. Em linguagem desenvolvida por Giddens (1983), isso ajuda a explicar as bases da agência - indivíduos agindo de forma proposital na persecução dos seus próprios interesses - ao invés de se submeterem docilmente às restrições da estrutura social circundante. Desse modo, considera-se tanto atores organizacionais quanto individuais como potenciais criadores de nova estrutura institucional. 
O APELO SOCIOECONÔMICO E A AÇÃO EMPREENDEDORA NO PROCESSO DE ESTRUTURAÇÃO DE CONFIGURAÇÕES PRODUTIVAS VINCULADAS À BIOENERGIA NO BRASIL

Fábio Freitas Schilling Marquesan - Joselito Brilhante Silva

Em relação à bioenergia, cabe aos empreendedores promoverem a produção e o consumo dos agrocombustíveis de forma descentralizada e não excludente em termos de rotas tecnológicas e de matérias-primas utilizadas, além de investirem na inclusão social (uma vez que o governo concede benefícios para tanto) pela compra de parcela da matéria-prima de produtores de agricultura familiar e em miniusinas (que primam pela produção de combustível em pequena escala, para abastecer comunidades isoladas, tornando-as autossuficientes energeticamente), para que, assim, surjam novas empresas no setor e soluções inovadoras com padrão de qualidade elevado e tecnologia de ponta, e a população seja sensibilizada e passe a usar a energia renovável.

\section{CONSIDERAÇÕES FINAIS}

Este ensaio teórico problematiza o que ficou denominado de apelo socioeconômico associado à ação empreendedora dirigida à estruturação de determinadas configurações produtivas, orientadas à exploração de bioenergia no Brasil pela abordagem do empreendedorismo institucional e das inovações sociais.

Nas três seções constituintes foram levantados elementos que mostraram que na relação da bioenergia com o empreendedorismo cabe aos empreendedores a produção, o consumo e os investimentos na inclusão social. Os processos de mudanças institucionais conduzem essas inovações sociais no campo da atuação prática, tendem a direcionar o estímulo quanto à adoção ou não de fontes alternativas de produção bioenergética, bem como promovem a reestruturação de antigas estruturas destinadas a abarcarem questões de cunho socioambiental. 0 apelo socioeconômico da produção bioenergética no Brasil vai além das questões eminentemente técnicas ou de potencialidade pela grande área e pelo uso intensivo de tecnologia. Existe uma plêiade de fatores sociais que precisam ser observados quando consideradas as relações socioeconômicas do arranjo produtivo para que não se deteriorem elementos essenciais, tais como a educação, a saúde e o meio ambiente.

Espera-se que este ensaio tenha proporcionado subsídios acerca da reflexão que deve perpassar a busca de soluções consensuais e negociadas para os problemas que foram levantados na primeira parte do texto quanto aos problemas da exploração da bioenergia no Brasil, embora não se tenha apresentado soluções técnicas ou novas formas de pensar sobre o tema, haja vista que não foi a isto que o presente escrito esteve endereçado.

Considerado o percurso metodológico de caráter ensaístico, este texto apresenta-se como um veículo indicativo de que a vinculação do apelo socioeconômico à figura do empreendedor como promotor da mudança nos processos de estruturação das configurações produtivas pode levar a transformações de ordem social. Para isso, apresenta-se a proposição de uma reflexão sobre as soluções que têm sido desenvolvidas para resolver, de forma sustentável, os problemas relacionados à exploração da bioenergia no Brasil.

\section{REFERÊNCIAS}

ARNDT, C.; HENLEY, G.; HARTLEY, F. Bioenergy in Southern Africa: An opportunity for regional integration? Development Southern Africa, v. 36, n. 2, p. 145-154, 2019.

BARATTER, M. A.; FERREIRA, J. M.; COSTA, M. C. Empreendedorismo institucional: considerações sobre imersão e mecanismo da teorização. In: ENCONTRO DA ASSOCIAÇÃO NACIONAL DE PÓS-GRADUAÇÃO EM ADMINISTRAÇÃO, 33., 2009. São Paulo, SP, 2009. 
O APELO SOCIOECONÔMICO E A AÇÃO EMPREENDEDORA NO PROCESSO DE ESTRUTURAÇÃO DE CONFIGURAÇÕES PRODUTIVAS VINCULADAS À BIOENERGIA NO BRASIL

Fábio Freitas Schilling Marquesan - Joselito Brilhante Silva

BECKERT, J. Agency, entrepreneurs, and institutional change. The role of strategic choice and institutionalized practices in organizations. Organization Studies, v. 20, n. 5, p. 777-799, 1999.

BERGER, P. L.; LUCKMANN, T. The social construction of reality: a treatise. Penguin, 1979.

BRUNSTEIN, J.; RODRIGUES, A. L.; KIRSCHBAUM, C. Inovação social e empreendedorismo institucional: a ação da ONG "Ação Educativa" no campo educacional da cidade de São Paulo. Organizações \& Sociedade, v. 15, n. 46, p. 119-136, 2008.

CASSOL, D. Bioenergia, para quem. MST Informa - Revista Sem Terra, ed. 38, 2007.

CLOUTIER, J. Qu'est-ce que l'innovation sociale? Montréal: Crises, 2003. p. 1-46.

DIMAGGIO, P. J.; POWELL, W. W. The iron cage revisited: Institutional isomorphism and collective rationality in organizational fields (American Sociological Review, 1983). Advances in Strategic Management, v. 17, p. 143-166, 2000.

DIMAGGIO, P. J. Interest and agency in institutional theory. In: ZUCKER, L. G. (ed.). Institutional patterns and organizations. Cambridge, MA: Ballinger, 1988. p. 3-21.

DOMAC, J.; RICHARDS, K.; RISOVIC, S. Socio-economic drivers in implementing bioenergy projects. Biomass and Bioenergy, v. 28, n. 2, p. 97-106, 2005.

EISENHARDT, K. M. Agency-and institutional-theory explanations: The case of retail sales compensation. Academy of Management Journal, v. 31, n. 3, p. 488-511, 1988.

FILION, L. J. Empreendedorismo: empreendedores e proprietários-gerentes de pequenos negócios. Revista de Administração, v. 34, n. 2, p. 5-28, 1999.

GABOR, D. Innovations: scientific, technological, and social. New York: Oxford University Press, 1970.

GIDDENS, A. Comments on the theory of structuration. Journal for the Theory of Social Behaviour, v. 13, n. 1, p. 75-80, 1983.

GREENWOOD, R.; SUDDABY, R.; HININGS, C. R. Theorizing change: The role of professional associations in the transformation of institutionalized fields. Academy of Management Journal, v. 45, n. 1, p. 58-80, 2002. GRESSHOFF, P. M.; RANGAN, L.; INDRASUMUNAR, A.; SCOTT, P. T. A new bioenergy crop based on oil-rich seeds from the legume tree Pongamia pinnata. Energy Emission Control Technol, v. 5, p. 19-26, 2017.

HARDY, C.; MAGUIRE, S. Institutional entrepreneurship. The Sage Handbook of Organizational Institutionalism, v. 1, p. 198-217, 2008.

HILBERT, Jorge A.; GALLIGANI, Sofia. Impactos socioeconómicos en la producción de bioenergía. Buenos Aires: Inta, 2015.

LECA, B.; BATTILANA, J.; BOXENBAUM, E. Agency and institutions: a review of institutional entrepreneurship. Cambridge, MA: Harvard Business School, 2008. p. 8-96.

LÉVESQUE, B. Empreendedor coletivo e economia social: outra forma de empreender. Revista Virtual de Gestão de Iniciativas Sociais, v. 1, p. 44-64, 2004.

MACHADO-DA-SILVA, C. L.; GONÇALVES, S. A. Nota técnica. A teoria institucional. In: CLEGG, S.; HARDY, C.; NORD, W. Handbook de estudos organizacionais. 2. ed. São Paulo: Atlas, 2006. p. 220-226.

MARSDEN, R.; TOWNLEY, B. Introdução: a coruja de Minerva - reflexões sobre a teoria na prática. In: CLEGG, S.; HARDY, C.; NORD, W. Handbook de estudos organizacionais. 2. ed. São Paulo: Atlas, 2006. p. 31-60. MISOCZKY, M. C.; BÖHM, S. Do desenvolvimento sustentável à economia verde: a constante e acelerada investida do capital sobre a natureza. Cadernos Ebape.br, v. 10, n. 3, p. 546-568, 2012.

MURPHY, P. J.; COOMBES, S. M. A model of social entrepreneurial discovery. Journal of Business Ethics, v. 87, n. 3, p. 325-336, 2009.

PEREDO, A. M.; MCLEAN, M. Social entrepreneurship: A critical review of the concept. Journal of World Business, 41(1), p. 56-65, 2006.

PHILLS, J. A.; DEIGLMEIER, K.; MILLER, D. T. Rediscovering social innovation. Stanford Social Innovation Review, v. 6, n. 4, p. 34-43, 2008.

POL, E.; VILLE, S. Social innovation: Buzz word or enduring term? The Journal of Socio-Economics, v. 38, n. 6, p. 878-885, 2009.

SCHUTZ, A. Collected papers I. The Hague: Martinus Nijhoff, 1962.

SCOTT, W. R. Prefatory chapter: institutions and social innovation. In: HÄMÄLÄINEN, Timo J.; HEISKALA, Risto. Social Innovations, Institutional Change and Economic Performance. Cheltenham: Edward Elgar, 2007. p. 8-21.

SILVERMAN, D. The theory of organizations. London: Heinemann, 1970.

TAYLOR, J. B. Introducing Social Innovation. The Journal of Applied Behavioral Science, v. 6, n. 1, p. 69-77, mar, 1970. 
O APELO SOCIOECONÔMICO E A AÇÃO EMPREENDEDORA NO PROCESSO DE ESTRUTURAÇÃO DE CONFIGURAÇÕES PRODUTIVAS VINCULADAS À BIOENERGIA NO BRASIL

Fábio Freitas Schilling Marquesan - Joselito Brilhante Silva

TOLBERT, P. S.; ZUCKER, L. G. A institucionalização da teoria institucional. In: CLEGG, S.; HARDY, C.; NORD, W. Handbook de Estudos Organizacionais. 2. ed. São Paulo: Atlas, 2006. p. 194-217.

VAILLANCOURT, Y. Centre de Recherche sur les Innovations Sociales (Crises). Laboratoire de Recherche sur les Pratiques et les Politiques Sociales (LAREPPS). Quebec: UQAM, 2008.

VENEMA, Bert. Transferring Climate Change Mitigation - a case study of the Clean Development Mechanism in Colombia and Peru from 2005 until 2017 (Master's thesis), 2018.

YADAV, P.; PRIYANKA, P.; KUMAR, D.; YADAV, A.; YADAV, K. Bioenergy Crops: Recent Advances and Future Outlook. In: Prospects of Renewable Bioprocessing in Future Energy Systems, Springer, Cham, p. 315-335, 2019.

ZUCKER, L. G. The role of institutionalization in cultural persistence. American Sociological Review, v. 42, n. 5, p. 726-743, 1977. 